\title{
Influence of Synthesis and Processing Parameters of the Columbite Precursor on the Amount of Perovskite PMN
}

\author{
A.A. Cavalheiro*, M.A. Zaghete, C.O. Paiva Santos, J.A. Varela, E. Longo \\ anstituto de Química, UNESP, C.P. 355, 14801-970 Araraquara - SP, Brazil \\ ${ }^{\mathrm{b}}$ Departamento de Química, UFSCar, C.P. 676, 13560-900 São Carlos - SP, Brazil
}

Received: April 1, 1999; Revised: July 13, 1999

\begin{abstract}
Columbite route for synthesis of $\mathrm{P}_{3} \mathrm{MgNb}_{2} \mathrm{O}_{9}$ ( $\mathrm{PMN}$ ) allows the suppression of secondary phases in PMN powders. These phases, having low dielectric constant, affect negatively the dielectric properties of PMN ceramics. Aiming to get reactive PMN powders, the partial oxalate method was used to precipitate lead oxalate over $\mathrm{MgNb}_{2} \mathrm{O}_{6}$ particles. The columbite (NM) powders were prepared using polymeric precursor based on Pechini's method. Two processing routes were used to prepare PMN powders. In the first one the NM-lead oxalate co-precipitate was washed in water and ethanol and calcined at several temperatures. In the second route, the NM-lead oxalate co-precipitate was washed in water and isopropyl alcohol, ball milled for $30 \mathrm{~min}$ and calcined at several temperatures. The second route leads to practically pyrochlore free PMN. Powders morphologies observed by SEM showed the formation of agglomerates, which sizes depend on the processing route.
\end{abstract}

Keywords: synthesis, columbite, PMN, Perovskite

\section{Introduction}

Lead Magnesium Niobate (PMN) is a classical relaxor ferroelectric ceramic with the composition of $\mathrm{Pb}\left(\mathrm{Mg}_{1 / 3} \mathrm{Nb}_{2 / 3}\right) \mathrm{O}_{3}$. Contrary to ordinary ferroelectric, which exhibit an abrupt change in the structure and properties at the Curie temperature $\left(\mathrm{T}_{\mathrm{C}}\right)$, the ferroelectric relaxors exhibit a large range transition with maximum dielectric constant and temperature for this maximum $\left(\mathrm{T}_{\mathrm{m}}\right)$ dependent on frequencies ${ }^{1}$. The large interest in studying this material is due to its low sintering temperature $\left(\approx 1000{ }^{\circ} \mathrm{C}\right)$, ferroelectric relaxor effect, electrostrictive properties, and high dielectric constant $\left(\mathrm{k}_{\mathrm{m}} \approx 20,000\right)$ allowing the increase in the volumetric efficiency of capacitors ${ }^{2,3}$. However, the formation of the perovskite PMN is very sensitive to the synthesis process. When PMN is prepared by conventional mixing of oxides, there is formation of a stable parasite phase, named pyrochlore, which degrades the dielectric properties of PMN ceramics ${ }^{4,5}$.

Since that the formation of the pyrochlore phase is related to the chemical reactivity between the lead and niobium oxides, Swartz and Shrout ${ }^{2}$ used the columbite route in preparing PMN. This method considers two stages: the first one consists in reaction of $\mathrm{MgO}$ and $\mathrm{Nb}_{2} \mathrm{O}_{5}$ to form the $\mathrm{MgNb}_{2} \mathrm{O}_{6}(\mathrm{NM})$ phase, named columbite. The second stage consists in reacting the NM phase with $\mathrm{PbO}$. This method allowed obtaining PMN powders with $98 \%$ of perovskite phase $\mathrm{e}^{2,6}$. The intermediate columbite phase should have a single crystalline phase with high surface area to give reactivity for reaction with $\mathrm{PbO}$ forming $\mathrm{PMN}^{7-9}$.

The microstructure of polycrystalline ceramics is direct function of the powder processing and of the green compaction characteristics. Then, each step for the fabrication of PMN ceramics should be controlled to assure in obtaining desirable properties. Several factors, such as size and morphology of powder particles, chemical and structural homogeneities, densification and grain growth, are intimately related to these properties ${ }^{10-14}$.

Anderson and co-authors ${ }^{15}$ studied a new route for synthesis of PMN; it is based on the method proposed by Pechini ${ }^{16}$, involving a polymeric synthesis. This method allowed a perfect chemical homogeneity in the mixing of cations, lead in obtaining more reactive PMN powders with higher amount of perovskite phase due to low calcination temperatures. Other methods also permit in obtaining PMN at lower temperatures than Pechini's method, but they have high $\operatorname{cost}^{7,14}$.

The homogeneity of the mixing among NM particles and $\mathrm{PbO}$ is of great importance for perovskite $\mathrm{PMN}$ phase formation. The Partial Oxalate Method ${ }^{17}$ allows in obtain- 
ing a homogeneous powder with few amounts of secondary phases, which improves the final properties of PMN ceramic $^{18}$. The addition of $\mathrm{PbO}$ in excess during synthesis of PMN during the precipitation of $\mathrm{PbC}_{2} \mathrm{O}_{4}$ over the $\mathrm{NM}$ particles is to compensate the $\mathrm{PbO}$ evaporation during calcining and sintering. However, the excess can also promote the formation of large amount of agglomerates in the powder $^{19}$.

In this work, the effect of synthesis variables on the phase formation of PMN powders is studied. The PMN was synthesized by the formation of NM particles using Pechini's process followed by the precipitation of lead oxalate over the NM particles. The effect of thermal decomposition of lead oxalate as well as the milling of co-precipitate NM-lead oxalate was investigated.

\section{Experimental}

\subsection{Chemical synthesis}

The Pechini's method was used to prepare the columbite $\mathrm{MgNbO}_{5}$. A complex of niobium ammonium oxalate was dissolved in water and ammonium hydroxide was added until reaching $\mathrm{pH}$ between 9 and 10 for complete precipitation of a hydrated niobium oxide. The precipitate was washed in distilled water until negative test for oxalates by using $\mathrm{Pb}\left(\mathrm{NO}_{3}\right)_{2}$ solution. The niobium oxide precipitate, free from oxalates, was dissolved in water solution of citric acid under stirring and heating. After the complete dissolution of niobium oxide precipitates, ethylene glycol was added to promote estherification in the temperature range of 80 to $100{ }^{\circ} \mathrm{C}$.

The magnesium citrate solution was prepared by slow addition of basic magnesium carbonate to a citric acid water solution under stirring and heating, forming a magnesium citrate. Ethylene glycol was added to the magnesium citrate solution to promote estherification at temperature range of 80 to $100{ }^{\circ} \mathrm{C}$. The molar ration metal : citric acid : ethylene glycol used was of $1: 4: 16$ for both solutions. The solutions were standardized by gravimetry and then mixed in the proportion $\mathrm{Nb} / \mathrm{Mg}=2$ until getting homogeneous solution. The condensation was promoted at $250{ }^{\circ} \mathrm{C}$ until the formation of high viscous resin. This resin was pre-calcined at $400{ }^{\circ} \mathrm{C}$ for $2 \mathrm{~h}$ forming agglomerate powder, which was then ground in a mortar. The resulting powder was then calcined at $900{ }^{\circ} \mathrm{C}$ for $2 \mathrm{~h}$ in a box type furnace forming an agglomerated NM powder, which was ground in a zirconia ball mill containing isopropyl alcohol during $16 \mathrm{~h}$.

Partial oxalate method associated to the columbite NM was used to prepare the PMN phase. NM particles was kept in suspension in a lead nitrate water solution and oxalic acid was added slowly to this solution to promote quantitative precipitation of lead oxalate over the NM particles. The co-precipitate was decanted and washed by using of dis- tilled water to eliminate the remaining oxalic acid and nitrate ions.

The co-precipitate was used in two different routes for synthesis of PMN. A route named R1 corresponds to washing the co-precipitate in absolute ethanol, followed by drying and calcining in a box type furnace with air injection. The route named R2 corresponds to washing the co-precipitate in isopropyl alcohol, followed by milling during $30 \mathrm{~min}$ in an attrition mill using isopropyl alcohol as medium, drying the precipitates, pre-calcination and calcination. The pre-calcination was used to decompose slowly the lead oxalate and was made in three soaking temperatures: 350 ${ }^{\circ} \mathrm{C}$ for $1 \mathrm{~h}, 380{ }^{\circ} \mathrm{C}$ for $30 \mathrm{~min}$ and $400{ }^{\circ} \mathrm{C}$ for $20 \mathrm{~min}$. An excess of 3 weight $\%$ of $\mathrm{PbO}$ in relation to the mass of PMN was added in both routes.

\subsection{Characterization methods}

A simultaneous thermal gravimetric analysis and differential thermal analysis (TG/DTA - Netzsch, Gerbau), followed thermal decomposition of the lead oxalate precipitated on the NM particles. The samples were heated at $5{ }^{\circ} \mathrm{C} / \mathrm{min}$ from ambient to $1100{ }^{\circ} \mathrm{C}$ in flowing synthetic air $(30 \mathrm{~mL} / \mathrm{min}), \alpha-\mathrm{Al}_{2} \mathrm{O}_{3}$ standard was used.

The X-ray diffraction patterns was used to follow the formation and decomposition of crystalline phases and recorded by a Siemens D5000 diffractometer $(50 \mathrm{kV}$ $100 \mathrm{~mA}$ ) using $\mathrm{Cu}-\mathrm{K}_{\alpha}$-radiation. The scattering intensities were measured in a range of Bragg angle $2 \theta$ between $20^{\circ}$ and $60^{\circ}$ with a step size of $(2 \theta)=0.03$ and counts time of $1 \mathrm{~s}$. The software FIT/SOCABIM - Siemens Diffract AT version 3.11 was used to calculate the amount of perovskite phase. The integrated intensities of the perovskite (110) peak $\left(\mathrm{I}_{\mathrm{Pe}}\right)$ and the sum of most intense peaks of secondary phases $\left(\mathrm{I}_{\mathrm{Se}}\right)$ were used to calculate the relative amount of perovskite phase according to the equation:

$$
\% \mathrm{P}_{\mathrm{e}}=\frac{100 \mathrm{I}_{\mathrm{P}_{\mathrm{e}}}}{\mathrm{I}_{\mathrm{P}_{\mathrm{e}}}+\mathrm{I}_{\mathrm{S}_{\mathrm{e}}}}
$$

A Topcon Model Scanning Electron Microscopy was used to analyze powder morphologies. The sample powders were ultrasonic treated and recovered by gold for SEM Analysis. Surface areas were determined by the nitrogen adsorption/desorption technique (CG-2000) with the BET method.

\section{Results and Discussion}

The NM powder was calcined at $900{ }^{\circ} \mathrm{C}$ for $2 \mathrm{~h}$ and the measured BET surface area was $8.2 \mathrm{~m}^{2} / \mathrm{g}$. After attrition milling the surface area increased to $11.6 \mathrm{~m}^{2} / \mathrm{g}$ due to break of agglomerates formed during the calcination. The milling is necessary since it increases the surface reactivity and improves the contact between NM particles and the lead oxalate precipitates. The SEM micrograph of PMN parti- 
cles is shown in Fig. 1a indicating mean particle size of $0.1 \mu \mathrm{m}$. However, when lead oxalate is precipitated over these particles, there is formation of agglomerates of about $5 \mu \mathrm{m}$ in size as shown in Fig. $1 \mathrm{~b}$.

TG and DTA were used to analyze the powder containing lead oxide precipitated on the NM particles, as shown in Fig. 2. In the range from 320 to $340{ }^{\circ} \mathrm{C}$ occurs the decomposition of lead oxalate to lead carbonate and a large weight loss is observed in the TG curve as well as an exothermic peak in the DTA curve. The lead carbonate has a decomposition temperature in the range from 340 to $360{ }^{\circ} \mathrm{C}$. A shoulder in the TG curve identifies an endothermic peak centered at $350{ }^{\circ} \mathrm{C}$. An exothermic process occurs in the range from 360 to $840{ }^{\circ} \mathrm{C}$, without weight loss, associated to the solid state reaction between $\mathrm{PbO}$ and $\mathrm{NM}$. Above $840{ }^{\circ} \mathrm{C}$ there is an endothermic peak and weight loss associated to the $\mathrm{PbO}$ volatilization. These results indicate that the PMN is formed in the range from 600 to $840{ }^{\circ} \mathrm{C}$, however the best range for the kinetic of this solid state reaction is from 750 to $800{ }^{\circ} \mathrm{C}^{18}$.
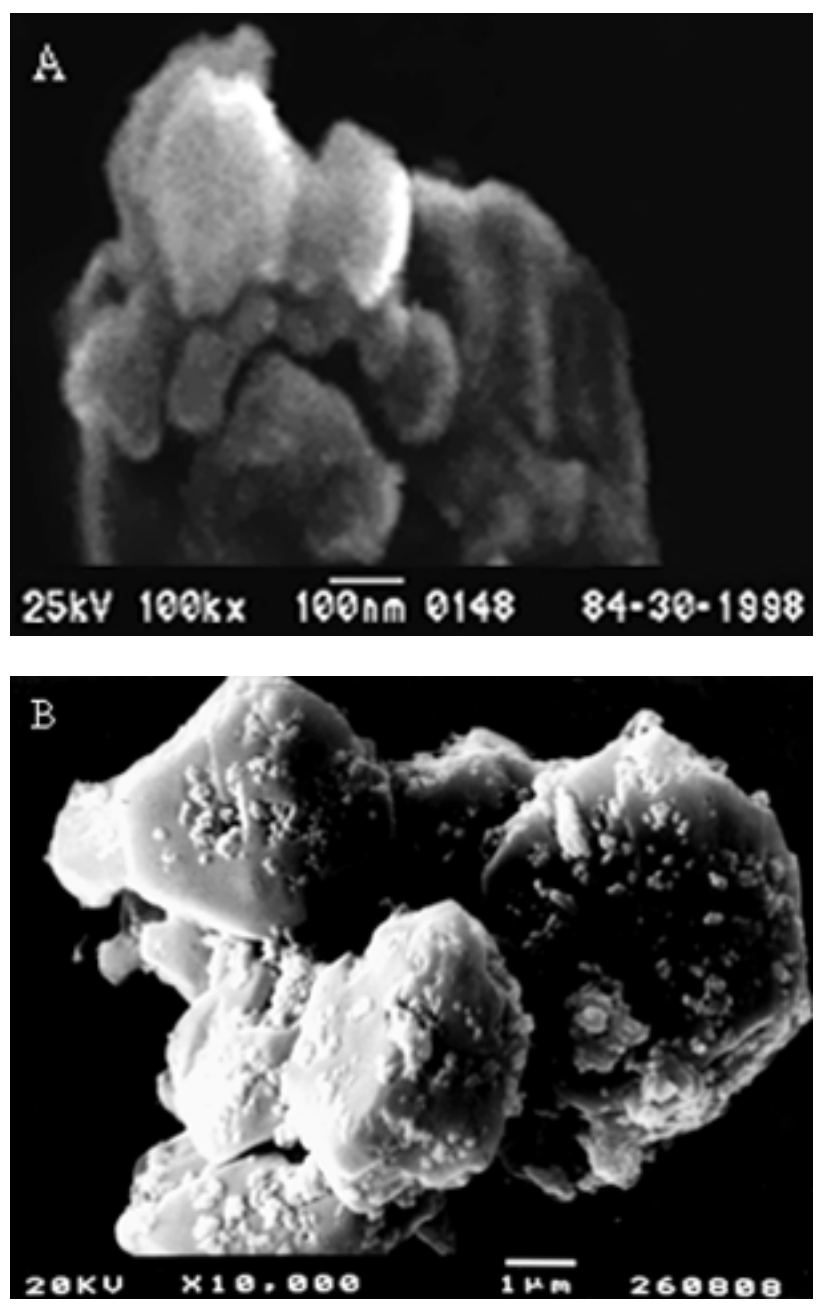

Figure 1. SEM micrographs obtained for: a) NM particles, b) NM-lead oxalate co-precipitate.
The X-ray diffraction pattern of the PMN powder prepared by the route 1 and calcined at $750{ }^{\circ} \mathrm{C}$ during 1 to $5 \mathrm{~h}$ are shown in Fig. 3. For short calcining times (1 and $2 \mathrm{~h}$ ) the dominant phase is the perovskite (phase \#1) with small amounts of secondary phases identified as pyrochlore phase $\mathrm{Pb}_{1.38} \mathrm{Nb}_{1.71} \mathrm{Mg}_{0.29} \mathrm{O}_{6.39}$ (phase \#2) and $\mathrm{PbO}$ (phase \#3). These phases could be associated to the incomplete formation of perovskite phase due to short time reaction. Increasing the calcination time the phases \#2 and \#3 decrease in intensities indicating more transformation into perovskite phase. Considering that the reaction among NM particles and $\mathrm{PbO}$ is controlled by the diffusion of $\mathrm{Pb}$ into the $\mathrm{NM}$ lattice, long time is necessary for complete reaction. Increasing the calcining temperature to $800{ }^{\circ} \mathrm{C}$ only phase $\# 2$, besides the perovskite phase appears in the X-ray pattern. In this case, the pyrochlore phase is formed during calcination and $\mathrm{PbO}$ is lost by volatilization.

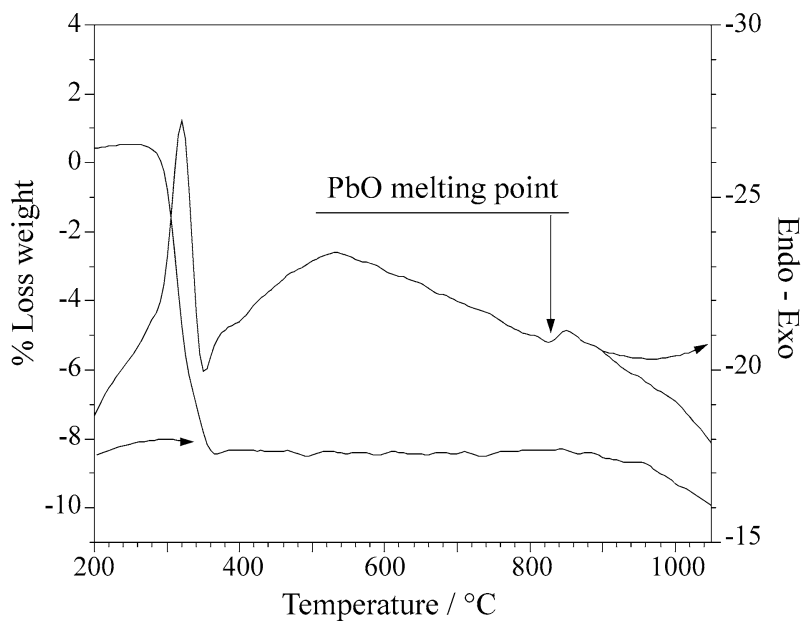

Figure 2. TG/DTA curves for the NM-lead oxalate co-precipitate.

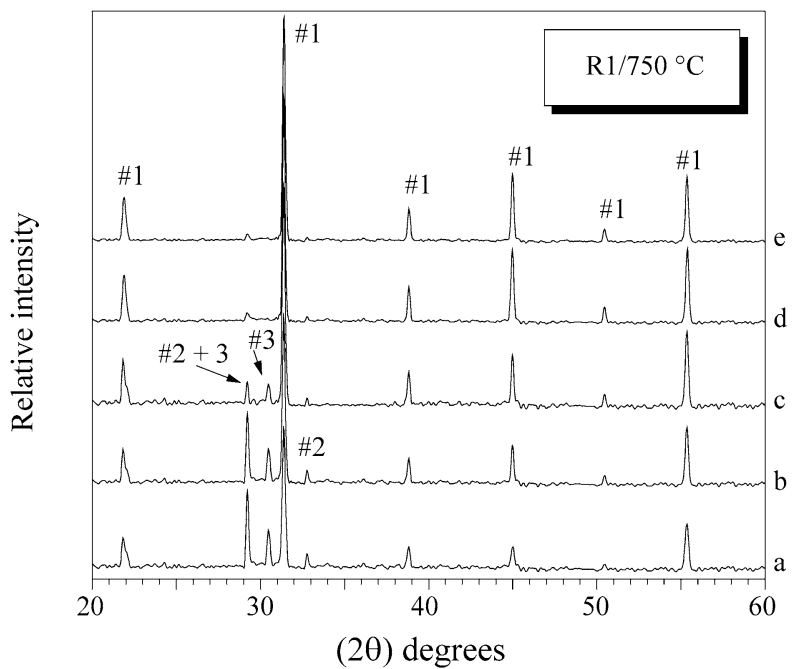

Figure 3. X-ray pattern for PMN powders prepared by route 1, calcined at $750{ }^{\circ} \mathrm{C}$ for: a) $1 \mathrm{~h}$, b) $2 \mathrm{~h}$, c) $\left.3 \mathrm{~h}, \mathrm{~d}\right) 4 \mathrm{~h}$, e) $5 \mathrm{~h}$. 
Table 1. Relation of present phases in the PMN powders prepared by both routes.

\begin{tabular}{lccc}
\hline Phase & Composition & Estructure & Reference (ICDD-PDF1) \\
\hline$\# 1$ & $\mathrm{~Pb}_{3} \mathrm{MgNb}_{2} \mathrm{O}_{9}$ & Cubic & $27-1199$ \\
$\# 2$ & $\mathrm{~Pb}_{1,38} \mathrm{Nb}_{1,71} \mathrm{Mg}_{0,29} \mathrm{O}_{6,39}$ & Cubic & $37-0071$ \\
$\# 3$ & $\mathrm{PbO}$ & Orthorhombic & $05-0570$ \\
\hline
\end{tabular}

The X-ray pattern of the PMN powder prepared by the route 2 and calcined at $750{ }^{\circ} \mathrm{C}$ during 1 to $5 \mathrm{~h}$ are shown in Fig. 5. In all calcination times the dominant phase is the perovskite PMN with small amounts of PbO. Since no pyrochlore phase was observed in powders prepared by this route, both the controlled decomposition of lead oxalate and the milling of agglomerates are important for the solid state reaction of $\mathrm{PbO}$ and $\mathrm{NM}^{20}$. Higher calcination tem-

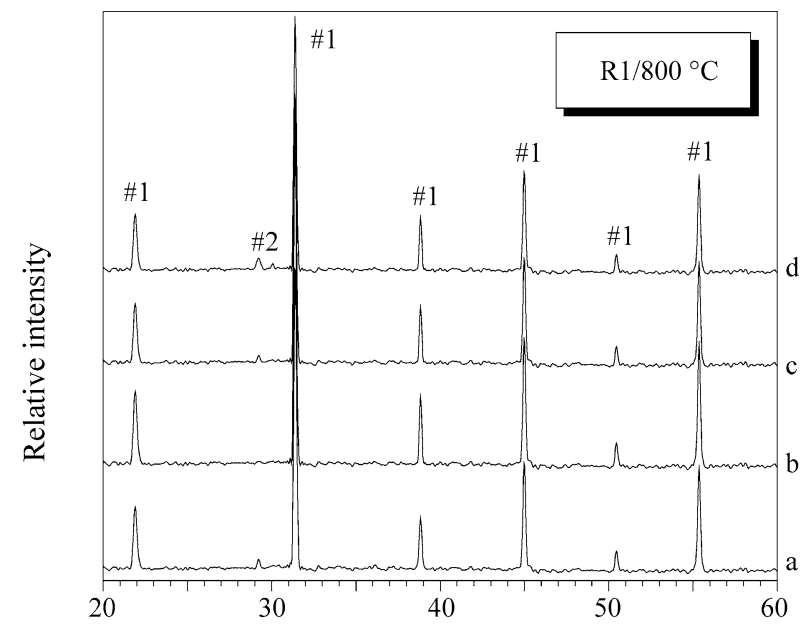

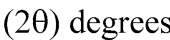

Figure 4. X-ray pattern for PMN powders prepared by route 1, calcined at $800{ }^{\circ} \mathrm{C}$ for: a) $1 \mathrm{~h}$, b) $2 \mathrm{~h}$, c) $\left.3 \mathrm{~h}, \mathrm{~d}\right) 4 \mathrm{~h}$.

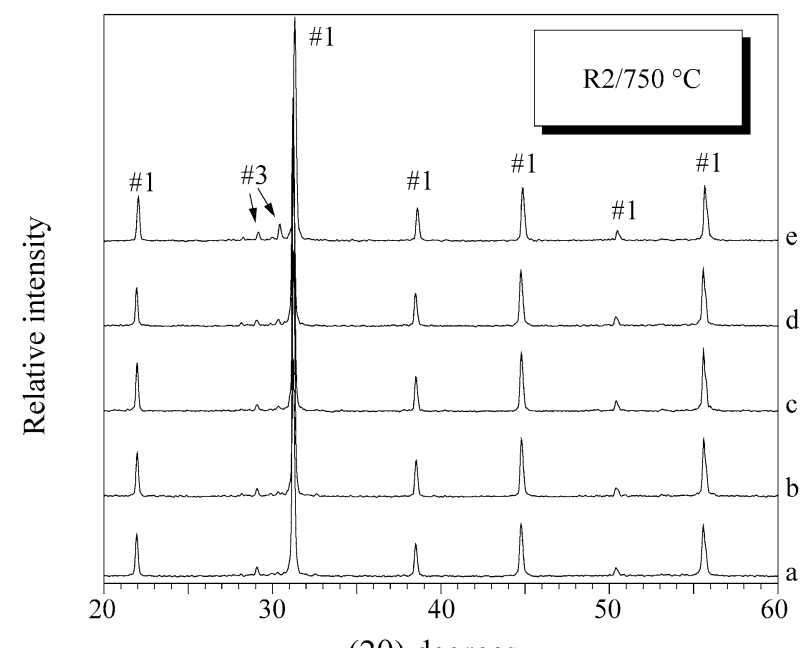

(20) degrees

Figure 5. X-ray pattern for PMN powders prepared by route 2, calcined at $750{ }^{\circ} \mathrm{C}$ for: a) $1 \mathrm{~h}$, b) $2 \mathrm{~h}$, c) $3 \mathrm{~h}$, d) $4 \mathrm{~h}$, e) $5 \mathrm{~h}$. perature $\left(800{ }^{\circ} \mathrm{C}\right)$ leads to decrease of the $\mathrm{PbO}$ phase with calcination time due to volatilization of $\mathrm{PbO}$ as observed in the X-ray pattern of Fig. 6. For this route, even for 4 or $5 \mathrm{~h}$ of calcination there is no significant perovskite phase decomposition.

By comparing the PMN powders characteristics obtained from both routes it is concluded that route 2 allows the synthesis of PMN with optimized amount of perovskite

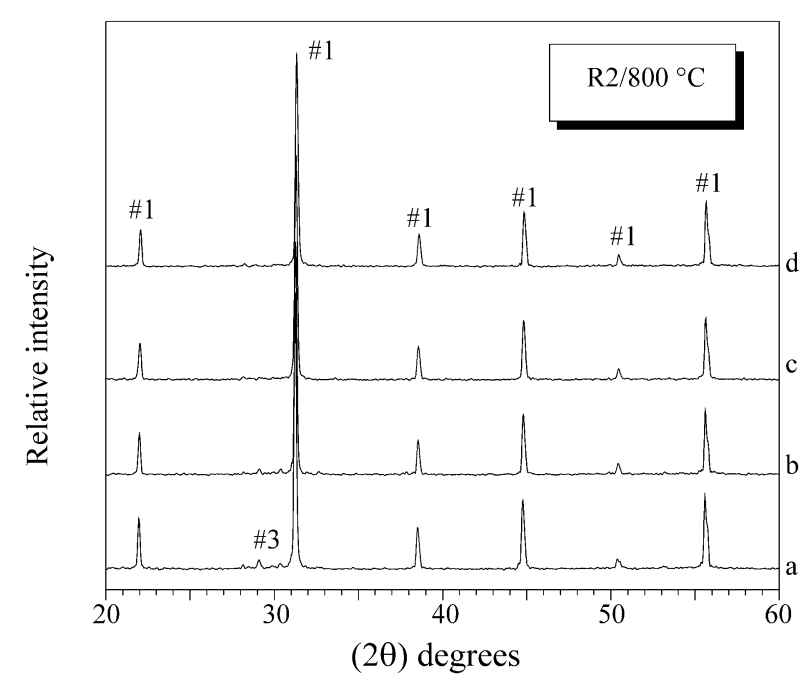

Figure 6. X-ray pattern for PMN powders prepared by route 2, calcined at $800{ }^{\circ} \mathrm{C}$ for: a) $1 \mathrm{~h}$, b) $2 \mathrm{~h}$, c) $3 \mathrm{~h}$, d) $4 \mathrm{~h}$.

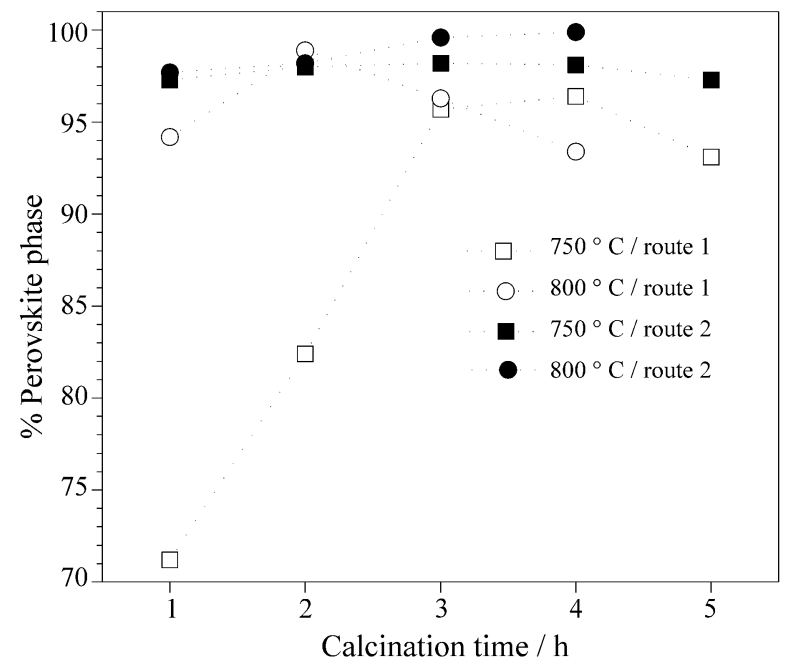

Figure 7. Evolution of perovskite phase amounts for PMN powders prepared by both routes, as function of the calcining conditions. 

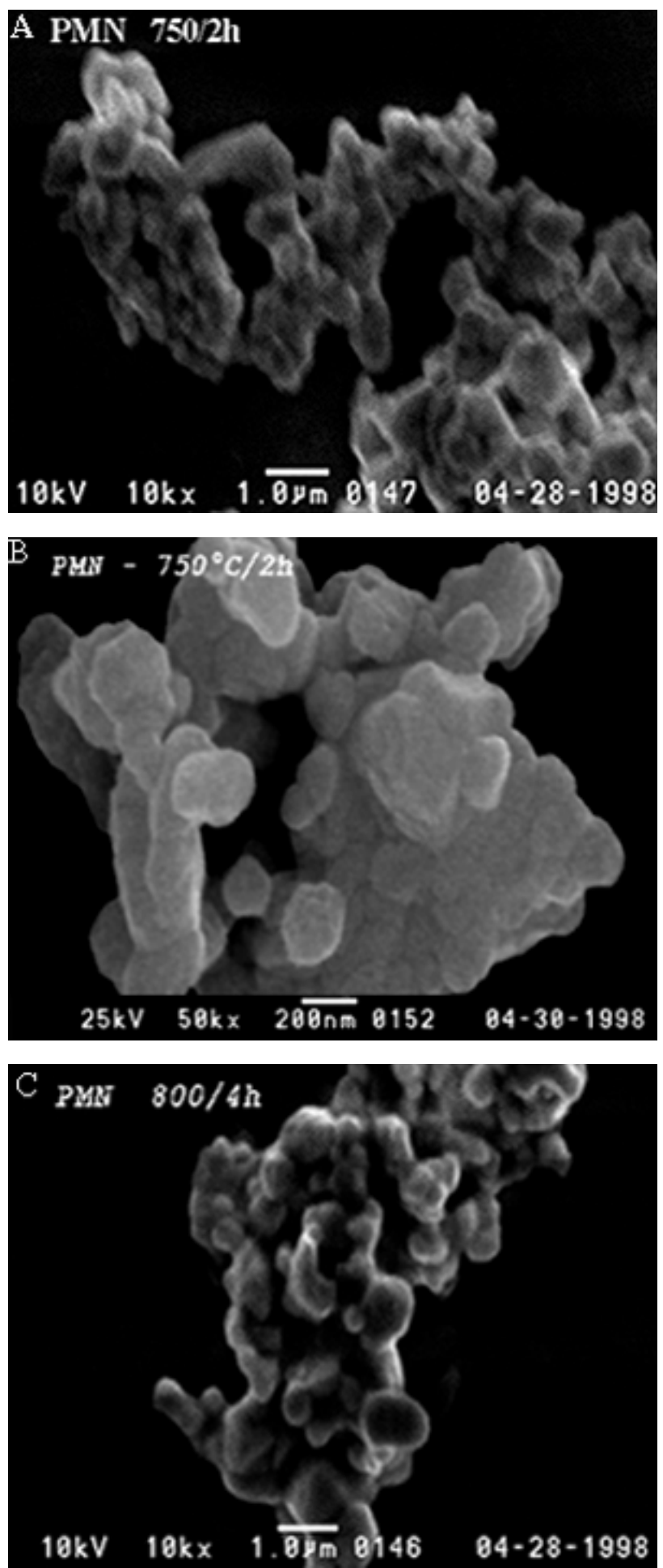

Figure 8. SEM micrographs for PMN samples: a) Route $1-750{ }^{\circ} \mathrm{C} / 2 \mathrm{~h}, \mathrm{~b}$ ) Route $2-750{ }^{\circ} \mathrm{C} / 2 \mathrm{~h}, \mathrm{c}$ ) Route $2-800{ }^{\circ} \mathrm{C} / 4 \mathrm{~h}$.

phase. A PMN powder with about $100 \%$ of perovskite phase was obtained using route 2 after calcining at $800{ }^{\circ} \mathrm{C}$ for $4 \mathrm{~h}$, as observed in Fig. 7. Free-pyrochlore PMN obtained in large range calcination conditions showed that method (route 2) is more efficient than oxide mixture ${ }^{20}$.
No significant change in surface areas was observed in synthesized PMN powders. Values of about $1.5 \mathrm{~m}^{2} / \mathrm{g}$ were observed for all conditions used in this work and could be related to the excess of $\mathrm{PbO}$ leading to the formation of agglomerates. However, the calcining conditions and the routes used for synthesize the PMN powder affects the morphology of the powders as shown in Fig. 8. Large agglomerates of about $5 \mu \mathrm{m}$ in size and large range of size particles (from $0,5 \mu \mathrm{m}$ to $3 \mu \mathrm{m}$ ) are observed when the PMN powder is obtained after calcining at $750{ }^{\circ} \mathrm{C}$ for $2 \mathrm{~h}$, as observed in Fig. 8a. However, for PMN powder prepared using route 2 and calcining in the same conditions, agglomerates of about $1 \mu \mathrm{m}$ and mean particle size about $0.2 \mu \mathrm{m}$ are observed, as shown in Fig. 8b. Increasing the calcining temperature to $800{ }^{\circ} \mathrm{C}$ for $4 \mathrm{~h}$, the mean particle size increase to $1 \mu \mathrm{m}$ and the average agglomerate size is about $5 \mu \mathrm{m}$, as observed in Fig. 8c. Then large agglomerates constitute the powders obtained using route 1 , where neither no milling of NM-lead oxalate co-precipitate was used nor any special decomposition for the co-precipitate was considered.

The morphology of the powders obtained from different routes and calcined in the same conditions are quite different, which allows concluding that the characteristics of the amorphous powder precursor determine the form and size of agglomerates. Heating at higher temperature of the precursor containing organic matter promotes the liberation of high amount of energy. Consequently, there is formation of several secondary stable phases, as well as large agglomerates, due to the presence of $\mathrm{PbO}$ in vapor phase. When the calcining is made in several stages, starting at lower temperature to eliminate the organic matter before the solid state reaction for the PMN perovskite phase formation at higher temperatures, the agglomerates are smaller and no secondary phases are formed. In both routes, flowing air during calcination favors the combustion of polymeric resin, the decomposition of lead oxalate, as well as the elimination of $\mathrm{CO}$ and $\mathrm{CO}_{2}$ formed by these reactions.

\section{Conclusions}

Polymeric precursor method was successful used to obtain single-phase NM particles with large surface area $\left(11.6 \mathrm{~m}^{2} / \mathrm{g}\right)$ after calcining at $900{ }^{\circ} \mathrm{C}$ for $2 \mathrm{~h}$ and attrition milling. This synthesis temperature is well below the conventional synthesis temperature using mixed oxides (above $\left.1000{ }^{\circ} \mathrm{C}\right)^{20}$. Pechini's and Partial Oxalate methods combined allowed the preparation of reactive PMN powder and secondary phase free. A special processing condition was used to obtain this powder. It consists of attrition milling of the lead oxalate precipitate over the NM particles followed by a special schedule for calcining the powder. 


\section{Acknowledgements}

The authors acknowledge FAPESP and CNPq (PRONEX) for financial support of this work.

\section{References}

1. Bokov, A.A. Ferroelectrics, v. 131, p. 49-53, 1992.

2. Smith, J.M.; Cross, L.E. Ferroelectrics, v. 1, p. 137140, 1970.

3. Swartz, S.L.; Shrout, T.R. Mat. Res. Bull., v. 17, p. 1245-1250, 1982.

4. Lejeune, M.; Boilot, J.P. Ceram. Int., v. 2, n. 8, p. 119-122, 1982.

5. Lejeune, M.; Boilot, J.P. Ceram. Int., v. 3, n. 8, p. 99-1038, 1983.

6. Chen, J.; Gorton, A.; Chan, H.M.; Harmer, M.P. J. Am. Ceram. Soc., v. 12, n. 69, p. 303-305, 1986.

7. Horowitz, H. J. Am. Ceram. Soc., v. 5, n. 71, p. 250-251, 1988.

8. Wang, H.C.; Schulze, W.A. J. Am. Ceram. Soc., v. 4, n. 73, p. 825-832, 1990.

9. Lu, C.-H.; Lee, J.-T. J. Ceram. Soc. Japan, v. 11, n. 103 , p. 1122-1128, 1995.
10. Lagrange, A. Mater. Sci. Eng., v. A, n. 109, p. 113 $-119,1989$.

11. Landin, S.M.; Schulze, W.A. J. Am. Ceram. Soc., v. 4, n. 73, p. 909-912, 1990.

12. Chen, J.C.; Harmer, M.P. J. Am. Ceram. Soc., v. 1, n. 73, p. 68-73, 1990.

13. Lin, L.J.; Wu, T.B. J. Am. Ceram. Soc., v. 5, n. 73, p. 1253-1256, 1990.

14. Ravindranathan, P.; Komarneni, S.; Roy, R. J. Am. Ceram. Soc., v. 4, n. 73, p. 1024-1025, 1990.

15. Anderson, H.V.; Pennel, M.J.; Guha, J.P. Advances in Ceramics, v. 21, p. 91-98, 1987.

16. Pechini, M.P. U.S. Patent n. 3.330.697, July 11, 1967.

17. Cavaco, M.C.S.; Santos, M.A.P.; Leite, E.R.; Carvalho, L.C.; Longo, E.; Varela, J. Anais do 37 C.B.C., Curitiba, PR, p. 717-724, 1993.

18. Cavalheiro, A.A. Dissertação de Mestrado, Inst. de Química, UNESP, Araraquara, SP, 1998.

19. Gupta, S.M.; Kulkarni, A.R. J. Mater. Res., v. 10, p. 953-961, 1995.

20. Kim, N.-K. Mater. Lett., v. 32, p. 127-130, 1997. 